\title{
Maxillary sinus - A tool for sex determination in the Nepalese population
}

\section{Singh PK' , Paudel RC ${ }^{2}$, Menezes RG ${ }^{3}$, Khanal $\mathrm{K}^{4}$}

'Pankaj Kumar Singh, Assistant Professor, Department of Forensic Medicine; ${ }^{2}$ Ram Chandra Paudel, Lecturer, Department of Radiodiagnosis and Imaging, Kathmandu University School of Medical Sciences; ${ }^{3}$ Ritesh G. Menezes, Professor, Forensic Medicine Division, Department of Pathology, College of Medicine, Imam Abdulrahman Bin Faisal University, Dammam, Saudi Arabia; ${ }^{4}$ Kishor Khanal, Assistant Professor, Department of Community Medicine, Kathmandu University School of Medical Sciences, Kathmandu University, Dhulikhel, Nepal.

\begin{abstract}
Background: In forensic science, skeletal examination is often done with primary focus on identification. Complete identification is a rare event in this type of examination. However, anthropological identification can be done in skeletal examination. Skull is the second best for determination of sex next to pelvis. Maxillary sinuses are paranasal sinuses, and a feature for sexual dimorphism which remains intact in partially charred. The study of maxillary sinus is best done on Computed Tomography.

Objectives: The primary objective of this study is to evaluate bilateral maxillary sinus for sexual dimorphism using Computed Tomography.

Methodology: A total of $104 \mathrm{CT}$ head cases were studied of which 52 were male and 52 female. The anterior posterior length, transverse width and height of bilateral maxillary sinus were measured in male and female through their DICOM images using inbuilt electronic calliper. Descriptive analysis for mean, paired $t$ test to compare right and left maxillary sinus in both male and female, and student $t$ test for compare male and female were used for analysing the value measured and calculated.

Results: Male maxillary sinus (Right $12.76 \pm 4.62 \&$ Left 12.39 \pm 3.81 ) was found be to larger than that of female (Right $12.16 \pm 4.78$ \& Left 11.80 \pm 4.49 ). Right and left maxillary sinus of both the sexes showed no significant difference when paired $t$ test was used. Using independent $t$-test showed no sexual dimorphism between the two sexes.

Conclusion: Maxillary sinus is not good tool for sex determination in Nepalese population. However further studies could be done on larger population sample, as smaller sample size could be the limitation of this study.
\end{abstract}

Key words: Anthropological Identification; Computed Tomography; Identification; Maxillary sinus; Skeletal examination; Sexual dimorphism.

DOI: https://doi.org/10.3126/jkmc.v8i2.28170

\section{INTRODUCTION}

A nthropological features and anthropometric measurements are used for the identification of skeletal remains. In practice, although anthropological features are commonly used with much difficulty in terms of subjectivity for identification, they do not always grease the wheels of a forensic expert's job in the long

Address for correspondence

Dr. Pankaj Kumar Singh

Assistant Professor

Department of Forensic Medicine

Kathmandu University School of Medical Sciences, Kathmandu University, Dhulikhel, Nepal

E-mail:drpankaj_s@yahoo.in run. In practice the opinions based on anthropological features are primarily based on personal experience and not always evidence-based. On the other hand, opinions based on anthropometric measurements are objective.

Sex determination is one of the primary objectives of the examination of skeletal remains. The importance of obtaining data on sexual morphology from complete and parts of bones is routine task in the field of forensic anthropology. The skull is the best bone considered for sex determination after the pelvis ${ }^{1,2}$.

In forensic cases, the skull is customarily examined for sex determination as it has great resistance to adverse 
environmental conditions with eventual solidity of dimorphic features. Such sexual dimorphism of bones is, however, reliable only after attainment of puberty ${ }^{2,3}$. Several authors have studied various parts of the skull in search of anthropometric data for sexual dimorphism in various populations, and have come up with important suggestions as to the appropriate sexually dimorphic measurements and circumstances wherein a part must be focused ${ }^{3-5}$. One such suggestion has been the examination of the maxillary sinus, as it remains intact in partially charred victims, wherein other features get damaged or destroyed ${ }^{2,6-8}$. Maxillary sinuses are paranasal air spaces, present in the maxillary bone of the skull and are of various shapes and sizes ${ }^{8}$. They appear at the end of the second month of the intrauterine life and mature at the age of about 20 years ${ }^{9}$.

Radiographic techniques have long been used in forensic cases since time immemorial; one may recall the demonstration of lead bullets in a victim's head by Prof. Arthur Schuster of Owens College, Manchester, in 1896, one year subsequent to the discovery of X-ray. Nowadays forensic experts use radiographic techniques on a regular basis for various purposes. Inventions like CT (Computed Tomography), MRI (Magnetic Resonance Imaging) have further increased the importance of radiology in forensic investigations. Thus taking into account, the importance of radiology in forensic investigations, and maxillary sinus as a tool for identification, we intend to use it for our present study. Computed Tomography (CT)of the head and in it studying maxillary sinus is purposed, cause $\mathrm{CT}$ are excellent to evaluate paranasal sinuses and the multi sectioning of CT permits unlimited virtual dissection with accurate measurement of its dimensions without physically damaging the specimen. The present study is not unique, considering it has been proposed and studied in different populations, though it is one of its kinds in Nepalese population.

\section{METHODOLOGY}

The present study is a cross sectional hospital-based study comprising of 104 head CT scan images of adult individuals above the age of 20 years. The study comprises of 52 male and 52 female samples, conducted at Kathmandu University School of Medical Sciences, Dhulikhel, Nepal. On receiving approval from the Institutional Review Committee of the aforementioned institute, the study was conducted in accordance with ethical standards of the Declaration of Helsinki. The subjects included in this study were randomly selected, who needed a CT scan for the diagnostic purpose during the course of their treatment, between 2018 May to 2018 August. Volumetric scan was done on 128 slices
Simen Somatom Perspective Scanner at $5 \mathrm{~mm}$ thickness with $5 \mathrm{~mm}$ interval, the reconstruction was done at $1 \mathrm{~mm}$ thickness and the study was conducted on multi planner scan of axial, coronal and saggital view. Written consent for the data to be collected was obtained from the patient and /or patient party of 104 individuals included in this study. The following dimensions of the bilateral Maxillary Air Sinuses were measured directly on the computer on DICOM images using inbuilt Electronic Caliper in DICOM viewer software.

a. Anterior-posterior length of the maxillary sinus (APL): Maximum distance between the anterior most point and posterior most point of maxillary sinus on Saggital section. (Figure 1)

b. Transverse width of the maxillary Sinus (TW): Maximum distance perpendicular to the medial wall to outermost point of the lateral wall of the maxillary sinus on coronal section (figure 2).

c. Height of the maxillary sinus $(\mathrm{H})$ : Maximum distance between the roof of the sinus and the floor of the sinus on coronal section (figure 3 ).

All the above measurements were taken in centimeters and using a mathematical formula used by Sharma SK et al. $^{10}$ for calculating the volume of bilateral maxillary sinuses. The mathematical formula is given below.

$\{\text { Volume }=A P L \times T W \times H \times 0.52\}^{10}$

The data thus collected and calculated was entered into Microsoft Excel using Windows 7 version, which was compiled and prepared to be compatible for SPSS 20 software. Right and Left maxillary sinus mean values were compared with using paired T-test. Male-female differences were tested using independent t-test and statistical significance was defined at $=0.05$. Discriminant functional analysis was performed based on the result of independent t- test to assess the measurements of the maxillary sinuses.

\section{RESULTS}

The present study consists of 104 individuals of which 52 were males and 52 were females of Nepalese origin. The age range in the present study was 18 to 72 for males with mean $36.27( \pm 15.21)$ years, and 18 to 85 for females with mean $42.52( \pm 19.06)$ years (Table 1$)$.

Irrespective of the sex, the data collected in this study was continues in nature, meaning data are not restricted to defined separate values, with a normal distribution. Descriptive statistics of the maxillary sinus is described in table 2. The male maxillary sinus is slightly larger than its counterpart stated by the volume of maxillary sinus 
calculated using the mathematical formula. Of all the parameters used in the present study only the height of left the maxillary sinus showed sexual dimorphism. No significant difference was noted between male and female when student t-test was done except for height of left maxillary sinus where mean for males was $3.47 \pm 0.5$, for females was $3.22 \pm 0.4$ having the $p$-value 0.019 .

The right and left maxillary sinus were compared using paired t-test as detailed in table 3 and it states, no significantly different between right and left maxillary sinus except for APL in male where the p-value is 0.007 .

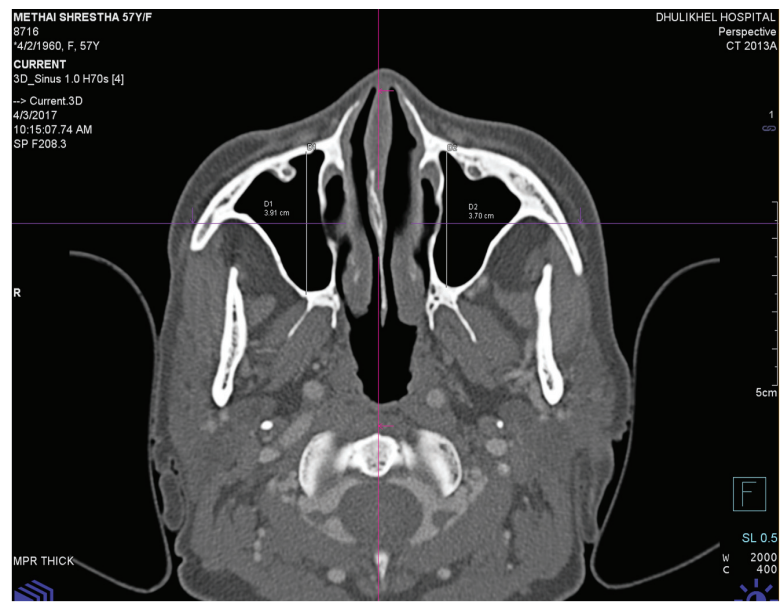

Figure 1: Anterior-posterior length of the maxillary sinus

Table 1: Age distribution of the participants

\begin{tabular}{ccccccc|}
\hline Sex & N & Minimum & Maximum & Mean & Std. Deviation \\
\hline Male & 52 & 18 & 72 & 36.27 & 15.21 \\
\hline Female & 52 & 18 & 85 & 42.52 & 19.06 \\
\hline
\end{tabular}

Table 2: Descriptive statistics of the maxillary sinus according to sex

\begin{tabular}{|c|c|c|c|c|c|c|c|c|c|}
\hline Sex & Statistics & $\begin{array}{l}\text { Right } \\
\text { height }\end{array}$ & Right APL & Right TW & $\begin{array}{c}\text { Right } \\
\text { Volume }\end{array}$ & $\begin{array}{c}\text { Left } \\
\text { height }\end{array}$ & Left APL & Left TW & Left Volume \\
\hline \multicolumn{10}{|l|}{ Male } \\
\hline Mean \pm SD & & $3.48 \pm 0.58$ & $3.36 \pm 0.36$ & $2.03 \pm 0.33$ & $12.76 \pm 4.62$ & $3.47 \pm 0.58$ & $3.27 \pm 0.37$ & $2.06 \pm 0.30$ & $12.39 \pm 3.81$ \\
\hline Median & & 3.47 & 3.34 & 2.03 & 11.95 & 3.45 & 3.26 & 2.06 & 12.25 \\
\hline Minimum & & 2.25 & 2.26 & 1.18 & 3.48 & 2.51 & 2.15 & 1.27 & 3.56 \\
\hline Maximum & & 5.15 & 4.09 & 3.19 & 27.75 & 5.09 & 3.95 & 2.65 & 22.11 \\
\hline \multicolumn{10}{|l|}{ Female } \\
\hline Mean $\pm S D$ & & $3.28 \pm 0.49$ & $3.40 \pm 0.44$ & $2.00 \pm 0.36$ & $12.16 \pm 4.78$ & $3.22 \pm 0.49$ & $3.40 \pm 0.44$ & $2.00 \pm 0.35$ & $11.80 \pm 4.49$ \\
\hline Median & & 3.29 & 3.47 & 2.01 & 12.24 & 3.23 & 3.45 & 2.02 & 10.41 \\
\hline Minimum & & 2.21 & 2.41 & 1.20 & 3.32 & 2.00 & 2.48 & 1.14 & 4.45 \\
\hline Maximum & & 4.45 & 4.23 & 3.21 & 26.37 & 4.35 & 4.26 & 2.91 & 23.96 \\
\hline t test & & 1.877 & -0.577 & 0.461 & 0.647 & 2.380 & -1.644 & 0.895 & 0.731 \\
\hline$p$-value & & 0.063 & 0.566 & 0.646 & 0.519 & 0.019 & 0.103 & 0.373 & 0.467 \\
\hline
\end{tabular}

SD: Standard deviation 
Table 3: Paired $\mathbf{t}$ test to compare right and left maxillary sinus in males and females

\begin{tabular}{|c|c|c|c|c|c|}
\hline Sex & Pairs & Mean & Std Deviation & $t$ test & p value \\
\hline \multirow{4}{*}{ Male } & Right height - left height & 0.008 & 0.301 & 0.198 & 0.844 \\
\hline & Right APL - Left APL & 0.088 & 0.225 & 2.833 & $0.007^{*}$ \\
\hline & Right TW - Left TW & -0.024 & 0.276 & -0.639 & 0.526 \\
\hline & Right volume - left volume & 0.359 & 2.458 & 1.054 & 0.297 \\
\hline \multirow{4}{*}{ Female } & Right height - left height & 0.062 & 0.317 & 1.423 & 0.161 \\
\hline & Right APL - Left APL & 0.003 & 0.261 & 0.069 & 0.945 \\
\hline & Right TW - Left TW & 0.002 & 0.203 & 0.061 & 0.951 \\
\hline & Right volume - left volume & 0.360 & 2.142 & 1.213 & 0.231 \\
\hline
\end{tabular}

*significant

\section{DISCUSSION}

One of the most difficult tasks in forensic practice is identification of skeletonized and decomposing human remains. In the process of identification sex determination is one of the most important steps. Next to the pelvis, the skull is preferred for sex determination; however in skull sexing is not reliable until after puberty. The methodologies used for gender determination is either morphological or morphometric ${ }^{3}$, of the two methodologies, morphometric has no inter-observer or intra-observer error.

In the present study, the results stated that the right and left maxillary sinus showed no significant differences expect for right and left APL in males and the mean of the volume calculated for right and left in male and female were; right $12.76 \pm 4.62$ and left $12.39 \pm 3.81$ in males and $12.16 \pm 4.78$ and $11.80 \pm 4.49$ in females. These findings reinstated that the males had larger volume and perimeter compared to that of females. The reason behind this could be best explained by Enlow ${ }^{11}$, who states that males require larger lungs than females to support their muscular build and body organs and to support the voluminous lungs males require larger airway. The physiological change in the airway of male and female is due to respiration need, thus affecting the size of the maxillary sinus to be larger in males. Many authors like $\mathrm{Kim}^{12}$ and Fernandes et $\mathrm{al}^{13}$ have concluded the finding in this study, right and left maxillary sinus bear no significant difference and males have larger maxillary sinus. In the present study, independent t test showed no significant difference in mean value between male and female except for one parameter, left maxillary height $(H)(t=2.380 ; p=0.019)$.

Fernandes et al. ${ }^{13}$, Uthman et al. ${ }^{8}$, Amin and Hussan ${ }^{14}$ and many other authors concluded that the maxillary sinus could be used to determine the sex in different populations. However, the predictability varied from population to population. Fernandes et al. ${ }^{13}$ studied dried skull of European and Zulu origin, have 90\% ethnical prediction and $79 \%$ gender prediction. Uthmanet al. ${ }^{8}$ conducted with $73.9 \%$ predictability, the study was conducted on CT images similar to ours. Similarly, Amin and Hussan ${ }^{14}$ also studied CT images on Egyptians population and concluded with a predictive accuracy of $70.8 \%$ in males and $62.5 \%$ in females. Ekizoglu et al. ${ }^{15}$ used discriminate function analysis on maxillary sinus in his study and detected $80 \%$ accuracy for female and $74.3 \%$ for male. The present study of our does not go with the study conducted by various authors, in different population reason being that our study showed not sexual dimorphism between male and female.

\section{CONCLUSION}

The study concludes that males have a larger voluminous maxillary sinus in comparison to females in the Nepalese population and that the maxillary sinus cannot be subjectively analysed to determine the sex of the individual. However, smaller sample size in this study is a limitation and therefore we suggest a similar study in a larger sample.

\section{REFERENCES}

1. Rogers TL. Determining the sex of human remains through cranial morphology. J Forensic Sci. 2005 May; 50(3):493-500. [PubMed]

2. Krogman, W.M. and Iscan, M.Y. (1986) The Human Skeleton in Forensic Medicine. 2nd Edition, Charles C. Thomas, Springfield. p 198-243. [FullText] 
3. Teke HY, Duran S, Canturk N, Canturk G. Determination of gender by measuring the size of the maxillary sinuses in computerized tomography scans. Surg Radiol Anat. 2007 Feb; 29(1):9-13. [PubMed]

4. Giles E, Elliot O. Sex determination by discriminant function analysis of crania. Am J Phys Anthropol. 1963 Mar; 21(1):53-68. [DOI]

5. Saini V, Srivastava R, Rai RK, Shamal SN, Singh TB, Tripathi SK. An Osteometric study of northern Indian population for sexual dimorphism in craniofacial region. J Forensic Sci. 2011 May; 56(3):700-5. [DOI]

6. Jehan M, Bhadkaria V, Trivedi A, Sharma SK. Sexual dimorphism of bizygomatic distance \& maxillary sinus using CT scan. IOSR-J Dent Med Sci. 2014 Mar; 13(3):91-5. [FullText]

7. Chandra Shekar BR, Reddy CV. Role of dentist in person identification. Indian J Dent Res. 2009 July; 20(3):356-60. [DOI]

8. Uthman AT, Al-Rawi NH, Al-Timimi JF. Evaluation of foramen magnum in gender determination using helical CT scanning. Dentomaxillo fac Radiol. 2012 Mar; 41(3):197-202. [PubMed]

9. Sidhu R, Chandra S, Devi P, Taneja N, Sah K, Kaur N. Forensic importance of maxillary sinus in gender determination: A morphometric analysis from Western Uttar Pradesh, India. Eur J Gen Dent. 2014; 3:53-6. [FullText]

10. Sharma SK, Jehan M, kumar A. Measurements of maxillary sinus volume and dimensions by computed tomography scan for gender determination. Journal of anatomical society of India; 2014 June; 63(1):36-42. [FullText]

11. Enlow DH. In: Facial Growth. $3^{\text {rd }}$ ed. Saunders Philadelphia;1990:6-7.

12. Kim GR. A morphological study of paranasal sinuses in Koreans. Yonsei Med J. 1962; 3:11-7. [FullText]

13. Fernandes CL. Forensic ethnic identification of Crania: the role of the maxillary sinus - A new approach. Am J Forensic Med Pathol. 2004 Dec; 25(4):302-13. [PubMed]

14. Amin MF, Hassan El. Sex identification in Egyptian population using Multidetector Computed Tomography of the maxillary sinus. J Forensic Leg Med 2012 Feb; 19(2):65-9. [PubMed]

15. Ekizoglu O, Ince $E$, Hocaoglu $E$, et al. The use of maxillary sinus dimensions in gender determination: a thin-slice multidetector computed tomography assisted morphometric study. J Craniofac Surg. 2014 May; 25(3):957-60. [DOI] 